\title{
How frequent is nocturia in medical students?
}

\author{
Burhan Coskun $^{1}$, Turgut Yurdakul ${ }^{2}$, Onur Kaygisiz ${ }^{1}$, Nizameddin Koca ${ }^{3}$, Ismet Yavascaoglu ${ }^{1}$ \\ ${ }^{1}$ Department of Urology, Uludag University School of Medicine, Bursa, Turkey \\ ${ }^{2}$ Uludag University School of Medicine, Bursa, Turkey \\ ${ }^{3}$ Department of Internal Medicine, University of Health Sciences, Bursa Yuksek Ihtisas Training and Research Hospital, Bursa, Turkey
}

\begin{abstract}
Objective. Nocturia is the most common lower urinary tract symptom and its prevalence increases with age. The frequency of nocturia and related bother are not widely investigated in young adults in the literature. In this study we aimed to investigate frequency, bothersome and relation of nocturia with anxiety in medical students. Methods. A questionnaire consisting of 19 items were sent to medical students via social media by using Survey Monkey ${ }^{\mathrm{TM}}$ software. Questions include demographic characteristics, fluid intake habits, voiding symptoms, and bother score related to nocturia. Also, Beck Anxiety Inventory was used to measure level of anxiety. Results. A total of 221 students replied the survey. The mean age was $20.7 \pm 2.10$. Forty-seven (21.3\%) students had nocturia. The rate of nocturia was $27.4 \%$ and $13.4 \%$ in women and men, respectively $(p=0.011)$. The frequency of nocturia per night was $80.2 \%, 17.3 \%$ and $2.2 \%(1,2,3$ times; respectively). While the frequency of nocturia was found to be related with bother scores there were no relation of gender with degree of bother. Conclusion. Nocturia is frequent in medical students, especially in women. Commonly, nocturia do not cause bother in young adults with one episode and it is not related with anxiety.
\end{abstract}

Eur Res J 2017;3(1):68-72

Keywords: Nocturia, young adults, bother

\section{Introduction}

Nocturia is a bothersome lower urinary tract symptom causing sleep disturbance. The International Continence Society (ICS) has defined nocturia as the complaint of up wake at night one or more time to void when each void is preceded and followed by sleep [1]. It is one of the most common lower urinary tract symptoms in adults. In a large scale study $48 \%$ of men and $54 \%$ of women found to have nocturia [2]. Despite the current definition of nocturia some researchers do not think only one void is clinically meaningful. In another study, the overall nocturia prevalence was $28.4 \%$ in 5,502 individuals with a definition of at least two wakes at night for voiding [3].

The number of voids per night increase with age however, young adults are not free of nocturia. According to the Third National Health and Nutrition Examination Survey (NHANNES III) the prevalance of nocturia in United States residents aging between 20 and 29 was $32 \%$ and $42 \%$ in men and women, respectively [4]. 
Nocturia may have negative effects on day time productivity due to sleep fragmentation. Furthermore it may adversely affect the quality of life [5]. This is more important in young adults who are prone to the high volume of workload. Frequent nocturia episodes can result in increased levels of anxiety. The association of nocturia with anxiety and depression is bidirectional. This association is more clear for depression however there are limited data for association between anxiety and nocturia [6].

In this study we aimed to investigate the prevalence and bother of nocturia among medical students as a primary objective. Our secondary objective was to evaluate whether there is a relation between nocturia and anxiety.

\section{Methods}

A questionnaire consisting of 19 items were sent to medical students via social media by using Survey Monkey ${ }^{\mathrm{TM}}$ software between the dates $29^{\text {th }}$ July 2016 and $3^{\text {rd }}$ August 2016. The questions regarding demographic characteristics included gender, age, height, weight, smoking and alcohol use, history of a systemic disease, daily use of a particular drug, presence of lower urinary tract symptoms (urgency, incontinence, voiding difficulties), mean fluid intake and mean sleep time. A specific question concerning the presence of nocturia was added to the questionnaire. We asked the following question depending on ICS definition of nocturia : "Do you wake for voiding while sleeping and you continue to sleep?" The frequency of nocturia is also included if present. The bother of nocturia was determined with the following question: "What is your degree of bother due to this condition?". The answer for this question was constructed with number from 0 to 10 ; in which " 0 " representing no bother and " 10 " a tremendous bother.

The anxiety level of the responders were determined with Beck Anxiety Inventory (BAE). This is a self-administrated scale consisting of 21 questions. Each question has four possible score ranging between 0 to 3 (0: not at all, 1: it did not bother me much, 2: It was not pleasant at times, 3 : it bothered me a lot.) [7]. The Turkish version of BAE was validated in university students by Tunay and Soygut [8].

\section{Statistical Analysis}

SPSS (v.23) software was used for statistical calculations. The descriptive data were quantitatively assessed, and given as numbers, and frequencies (\%). The correlations between the groups and responses to questions were analyzed using an appropriate chisquare test (Pearson chi-square or Fisher-Freeman-Halton exact test). All normally distributed data were presented as mean and standard deviation and compared with either the student's t-test. Non-normally distributed data were presented as median (minimum-maximum) with mean and standard deviation and were compared with MannWhitney $\mathrm{U}$ test. $p<0.05$ was specified as the level of statistical significance.

\section{Results}

A total of 221 medical students replied our survey. The mean age of the responders was $20.7 \pm 2.10$ years. Nighty-seven (43.89 \%) were man and 124 (56.11\%) were women. Forty-eight (21.7\%)students reported nocturia. While $39(80.2 \%)$ had a nocturia frequency of one, $8(17.3 \%)$ had two and only one $(2.2 \%)$ man had three times of nocturia (Figure 1). A total of 35 $(28.2 \%)$ were women and $13(13.4 \%)$ were man among the responders with nocturia $(p=0.009)$.

Comparison of the factors with and without nocturia is presented in Table 1. None of the factors besides gender were statistically significant across the groups.

The bother scores of the responders according to frequency of nocturia episodes are presented in Figure 2. A total of $21(43 \%)$ responders reported no bother (score of 0 ) of nocturia and 9 students (19.1\%) replied a bother score more than 5 over 10 . While the mean bother score in responders with a frequency of one was $1.31 \pm 2.14$ (0-9); this was $5.22 \pm 2.95$ in responders with two or three voids per night. This was found to be statistically significant $(p=0.001)$. The comparison of the degree of bother in men and women is listed in Table 2. The mean level of bother was $2.17 \pm 2.73(0$ 9) and $1.69 \pm 2.90(0-10)$ in men and women, respectively and the results were not statistically significant $(p=0.451)$.

\section{Discussion}

There are three main etiologic factors responsible for nocturia: i) nocturnal polyuria (over hydration at night, congestive heart failure), ii) decreased bladder capacity (neurogenic bladder, anxiety, bening prostatic 
Table 1. Comparison of the demographic characteristics and Beck anxiety inventory

\begin{tabular}{lccc}
\hline & Nocturia (+) & Nocturia (-) & $\boldsymbol{p}$ \\
\hline Mean age (years) & $20.9 \pm 1.9$ & $20.6 \pm 2.1$ & 0.714 \\
Gender & & & \\
$\quad$ Men & $13(13.4 \%)$ & $84(86.6 \%)$ & $\mathbf{0 . 0 0 9 *}$ \\
$\quad$ Women & $35(28.2 \%)$ & $89(71.8 \%)$ & \\
Mean BMI (kg/m $\left.{ }^{2}\right)$ & $22.53 \pm 3.5$ & $22.5 \pm 4.1$ & 0.977 \\
Smokers (n) & $3(6.4 \%)$ & $29(16.7 \%)$ & 0.075 \\
Alcohol consumers (n) & $12(25.5 \%)$ & $41(23.5 \%)$ & 0.779 \\
Mean daily fluid intake (ml) & $2031.91 \pm 11.30$ & $1849.42 \pm 802.07$ & 0.180 \\
Intake of fizzy drinks (n) & & & \\
$\quad$ Never & $5(10.6 \%)$ & $14(8.1 \%)$ & 0.109 \\
$\quad$ Seldom & $34(72.3 \%)$ & $103(59.2 \%)$ & \\
$\quad$ Frequent & $8(17.1 \%)$ & $57(32.7 \%)$ & \\
Mean length of sleep (hours) & $7.8 \pm 1.02$ & $7.5 \pm 1.1$ & 0.262 \\
History of a systemic illness (n) & $8(17.02 \%)$ & $26(14.9 \%)$ & 0.820 \\
Daily use of a drug (n) & $7(14.8 \%)$ & $20(11.4 \%)$ & 0.528 \\
Mean frequency of daytime voiding (n) & $4.69 \pm 1.87$ & $4.69 \pm 1.77$ & 0.997 \\
Urgency & $5(10.6 \%)$ & $8(4.6 \%)$ & 0.156 \\
Incontinence & $1(2.1 \%)$ & $1(0.6 \%)$ & 0.381 \\
PMR & $5(10.6 \%)$ & $6(3.4 \%)$ & 0.59 \\
Mean BAI score & $10.29 \pm 8.26$ & $10.44 \pm 9.9$ & 0.266 \\
\hline BMI-body ma
\end{tabular}

$\mathrm{BMI}=$ body mass index, $\mathrm{BAI}=$ Beck anxiety inventory, ${ }^{*} p<0.05$

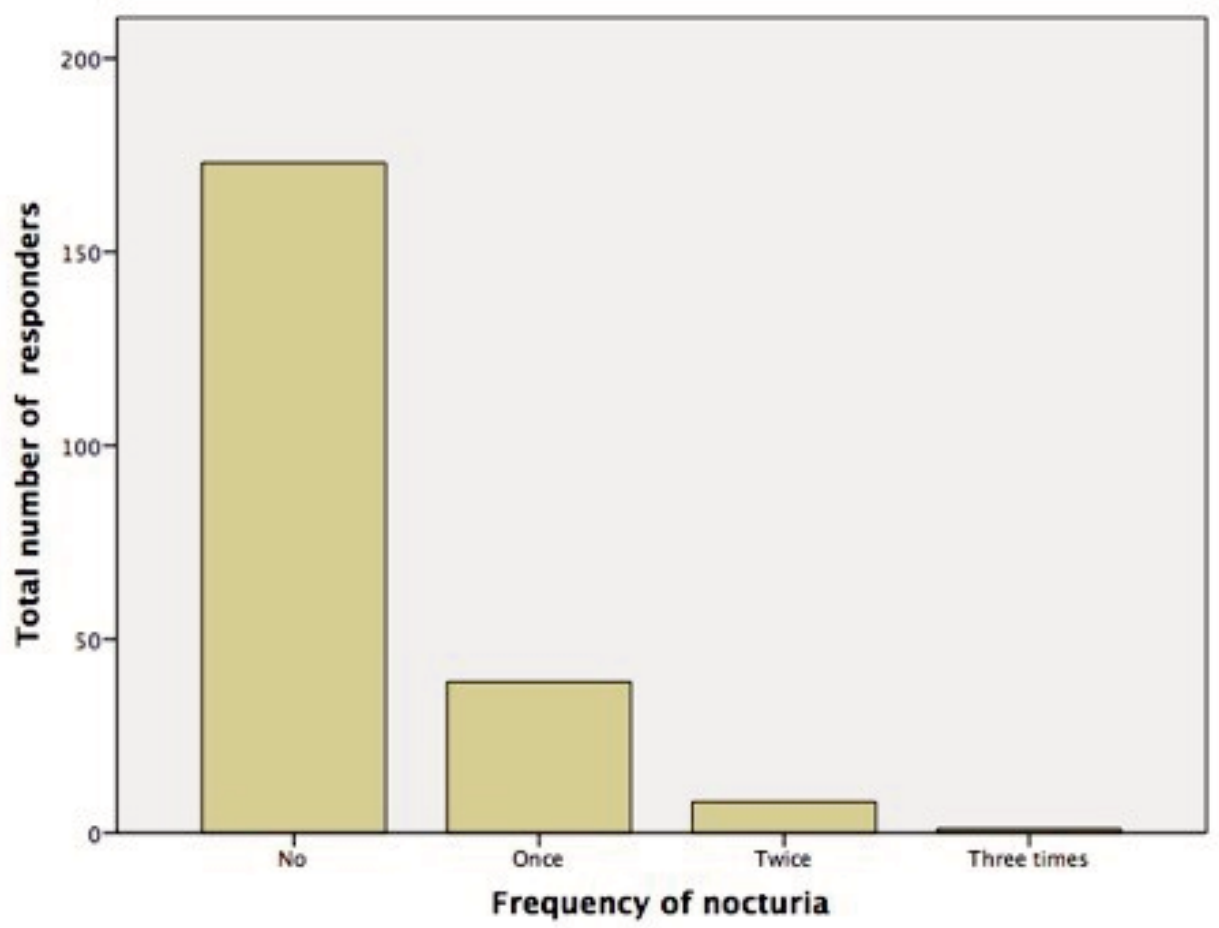

Figure 1. The distribution of the responders with or without nocturia.

obstruction), iii) global polyuria (primary polydipsia, diabetes) $[9,10]$. Not surprisingly these associated comorbidities are common in the aging population. Therefore, nocturia is recognized as a common lower urinary tract symptom of these individuals. Most of the research regarding nocturia has been developed on middle aged or elderly people though it is not a rare symptom in young adult population. Moreover, the bother of nocturia has not been widely investigated in this group. To best of our knowledge this is the first 
Table 2. Comparison of the bother scores with nocturia in women and men.

\begin{tabular}{lcc}
\hline Bother Score & Women & Men \\
\hline 0 & $14(41.17 \%)$ & $7(53.84 \%)$ \\
1 & $7(20.58 \%)$ & $1(7.69 \%)$ \\
2 & $2(5.58 \%)$ & $3(23.07 \%)$ \\
3 & $3(8.82 \%)$ & $0(0 \%)$ \\
4 & $2(5.58 \%)$ & $0(0 \%)$ \\
5 & $2(5.58 \%)$ & $1(7.69 \%)$ \\
6 & $1(2.94 \%)$ & $0(0 \%)$ \\
7 & $1(2.94 \%)$ & $0(0 \%)$ \\
8 & $2(5.58 \%)$ & $0(0 \%)$ \\
9 & $1(2.94 \%)$ & $0(0 \%)$ \\
10 & $0(0 \%)$ & $1(7.69)$ \\
\hline
\end{tabular}

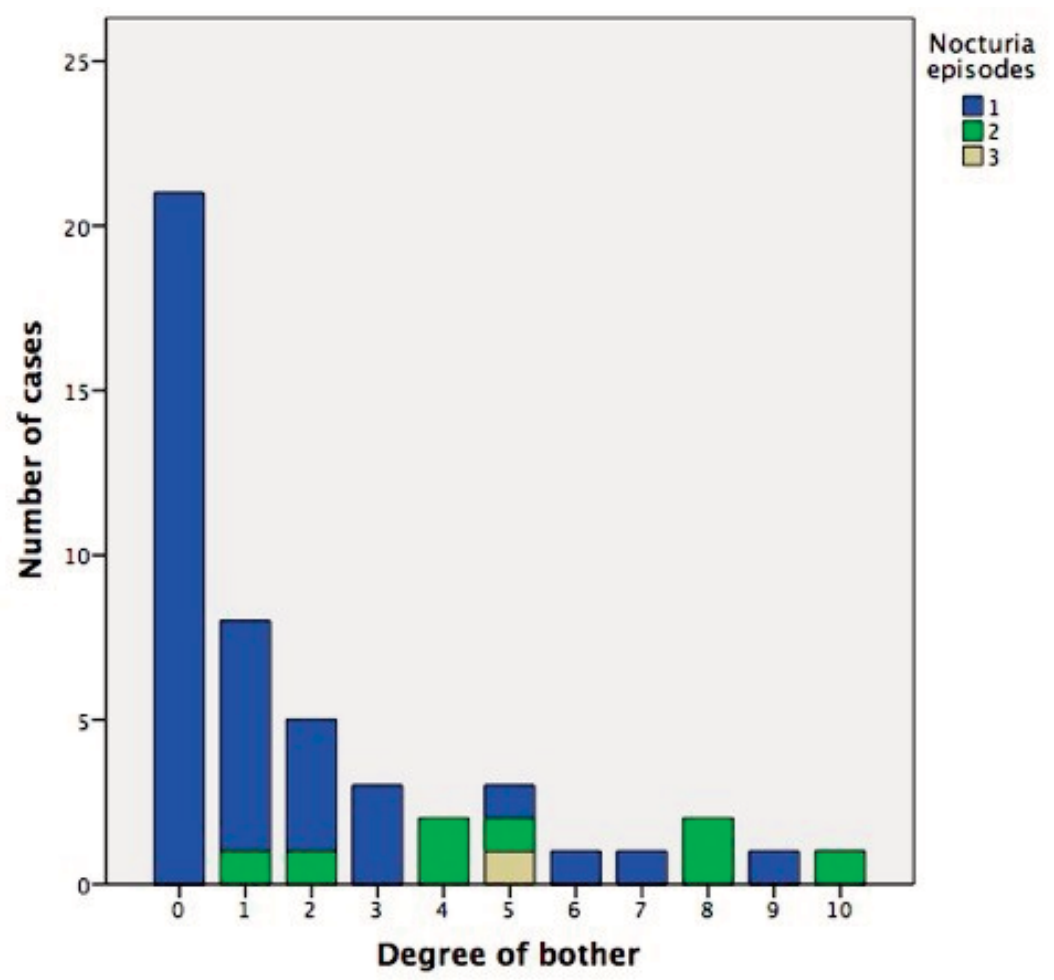

Figure 2. The bother scores of the responders according to frequency of nocturia episodes.

study with a focus on nocturia in medical students in Turkey.

Sleep is an important aspect of human life which is crucial for mental and physical health. Sleep deprivation due to nocturia is more important in younger population than elderly people. Young individuals particularly college students are prone to stressful conditions such as examinations. According to the results from this survey approximately one medical student in five had symptoms of nocturia according to the current definition of ICS. The rate of nocturia was $28.2 \%$ and $13.4 \%$ in women and men, respectively. Similarly, Bosch and Weis [11] reported a nocturia prevalence of $35 \%$ and $11 \%$ aged between
20 and 40 for women and men, respectively. The exact pathophysiology of female predominance is not clearly understood. Taking care of a child or baby was suggested as a related factor by Bosch and Weiss [11]. However, in our population none of the medical students had a baby. Also, increased rates of insomnia was speculated as a predisposition factor younger women [11].

The level of bother was related with frequency of nocturia episodes in most of the studies [12, 13]. Therefore, in some studies nocturia is defined with a criterion of at least two voids at night [13]. In the present study, approximately $80 \%$ of the patients reported a nocturia frequency of one and there was a 
correlation with nocturia episodes and bother. However, the level of the bother can change in individual basis. For example, in the present study while one man with two episodes of nocturia reported the maximum bother score; another man with three episodes replied a moderate score. This phenomenon was also reported by Kupelian et al.[4].

In most of the epidemiological studies, smoking, BMI, alcohol and soft drinks were found to be a prognostic factor for nocturia[4, 14]. Smoking may cause storage symptoms on the other hand increased levels of arginine-vasopressin may counter balance this negative effects [14]. In our survey we did not find any relation with any of these parameters. The longer periods of sleep and increased fluid intake may result in nocturia. However, these parameters were not found to be related with nocturia.

Depression and anxiety disorders may be important risk factors for nocturia. These disorders may be more relevant with nocturia for young population. An impairment in circadian rhythm of anti-diuretic hormone can explain pathophysiology of nocturia in these disorders [15]. In a study, risk of having nocturia was found to be 6 and 3 times higher in men and women with depression. We hypothesized anxiety scores will be higher in medical students with nocturia. However, BAI scores were not different across the students with or without nocturia.

There are some studies reporting a link between nocturia and survival. This may be clinically important in elderly population [4]. The importance of this phenomenon is still elusive in young population.

\section{The Limitations of the Study}

The major limitation of the study was the small sample size and lack of voiding frequency charts or bladder diaries to determine exact pathology of nocturia.

\section{Conclusions}

In conclusion, nocturia is a frequent symptom among medical students especially in women. In most of the cases the bother is related with the frequency of nocturia. The results from the current study suggest no role for anxiety in development of nocturia.

\section{Conflict of interest}

The authors disclosed no conflict of interest during the preparation or publication of this manuscript.

\section{Financing}

The authors disclosed that they did not receive any grant during conduction or writing of this study.

\section{References}

van Kerrebroeck P, Abrams P, Chaikin D, Donovan J, Fonda D, Jackson $\mathrm{S}$, et al. The standardisation of terminology in nocturia: report from the Standardisation Sub-committee of the International Continence Society. Neurourol Urodyn 2002;21:179-83.

[2] Irwin DE, Milsom I, Hunskaar S, Reilly K, Kopp Z, Herschorn $\mathrm{S}$, et al. Population-based survey of urinary incontinence, overactive bladder, and other lower urinary tract symptoms in five countries: results of the EPIC study. Eur Urol 2006;50:1306-14; discussion 1314-5.

[3] FitzGerald MP, Litman HJ, Link CL, McKinlay JB. The association of nocturia with cardiac disease, diabetes, body mass index, age and diuretic use: Results from the BACH survey. J Urol 2007; 177:1385-9.

[4] Kupelian V, Fitzgerald MP, Kaplan SA, Norgaard JP, Chiu GR, Rosen RC. Association of nocturia and mortality: results from the Third National Health and Nutrition Examination Survey. J Urol 2011;185:571-7.

[5] Weiss JP, Blaivas JG, Bliwise DL, Dmochowski RR, Dubeau CE, Lowe FC, et al. The evaluation and treatment of nocturia: a consensus statement. BJU Int 2011;108:6-21.

[6] Golabek T, Skalski M, Przydacz M, Swierkosz A, Siwek M, Golabek K, et al. Lower urinary tract symptoms, nocturia and overactive bladder in patients with depression and anxiety. Psychiatr Pol 2016;50:417-30.

[7] Leyfer OT, Ruberg JL, Woodruff-Borden J. Examination of the utility of the Beck Anxiety Inventory and its factors as a screener for anxiety disorders. J Anxiety Disord 2006;20:444-58.

[8] Tunay S, Soygut G. [The reliability and validity of Turkish brief measure of worry severity based on Turkish university students]. Turk Psikiyatri Derg 2009;20:68-74. [Article in Turkish]

[9] MacDiarmid S, Al-Shukri S, Barkin J, Fianu-Jonasson A, Grise $\mathrm{P}$, Herschorn S, et al.; BESIDE Investigators. Mirabegron as add-on treatment to solifenacin in patients with incontinent overactive bladder and an inadequate response to solifenacin monotherapy. J Urol 2016;196:809-18.

[10] Gratzke C, Bachmann A, Descazeaud A, Drake MJ, Madersbacher S, Mamoulakis C, et al. EAU Guidelines on the assessment of non-neurogenic male lower urinary tract symptoms including benign prostatic obstruction. Eur Urol 2015;67:1099-109. [11] Bosch JLHR, Weiss JP. The prevalence and causes of nocturia. J Urol 2010;184:440-6.

[12]Tikkinen KA, Johnson TM, 2nd, Tammela TL, Sintonen H, Haukka J, Huhtala H, et al. Nocturia frequency, bother, and quality of life: how often is too often? A population-based study in Finland. Eur Urol 2010;57:488-96.

[13] Hernandez C, Estivill E, Prieto M, Badia X. Nocturia in Spanish patients with lower urinary tract symptoms suggestive of benign prostatic hyperplasia (LUTS/BPH). Curr Med Res Opin 2008;24:1033-38.

[14] Yoshimura K, Terada N, Matsui Y, Terai A, Kinukawa N, Arai Y. Prevalence of and risk factors for nocturia: analysis of a health screening program. Int J Urol 2004;11:282-7.

[15] Asplund R, Henriksson S, Johansson S, Isacsson G. Nocturia and depression. BJU Int 2004;93:1253-6. 